\title{
HUBUNGAN TINGKAT PENGETAHUAN BIDAN TENTANG BLS (BASIC LIFE SUPPORT) DENGAN WAKTU TANGGAP PELAYANAN GAWAT DARURAT PADA PASIEN DI IRD OBGYN RSUD Dr. SOETOMO SURABAYA (The Correlation of Midwife's Knowledge About BLS (Basic Life Support) and Emergency Service Response Time On Patients In IRD Obgyn RSUD Dr. Soetomo Surabaya)
}

\author{
Rizki Amalia \\ Program Studi DIII Kebidanan, Universitas Nahdlatul Ulama Surabaya \\ email: amaliastikesyarsis@gmail.com
}

\begin{abstract}
The emergency service principle is Time Saving is Life Saving, primarily on the Priority 1 patients. The lack of midwife knowledge about BLS is one of factors that can decrease the response time in treating of Priority 1 patient, thus the risk of imperfection and mortality will be increasingly high. The purpose of this research was to know the correlation of midwife knowledge about BLS and the emergency service response time on the Priority 1 patients at the Emergency Unit of RSUD Dr Soetomo Surabaya. Method: Design of this research used observational analytical method with the Time Series approach. The population used nurses of Emergency Unit of RSUD Dr Soetomo Surabaya, on May 2017. The samples were 21 respondents by Total Sampling technique. The data collection was done by using questionnaire and observation sheets. After data were tabulated, then they were analyzed using the statistical test of Spearman's Rho Correlation with $\rho \leq 0.05$. Result: The results indicated that almost half (42.9\%) of respondents had good knowledge level and more than half (61.9\%) of respondents had the fast response time. The statistical test obtained results that there was correlation of the midwife knowledge level about BLS and the emergency service response time with $\rho=0.000$. Based on the results of this research, it could be concluded that the better knowledge level about BLS the faster the emergency service response time. It was needed to improve midwife knowledge about BLS by means the training and workshop so that the midwife response time increasingly fast.
\end{abstract}

Keywords: knowledge, behavior, breast self-examination

\begin{abstract}
Abstrak: Prinsip pelayanan gawat darurat adalah Time Saving is Life Saving, terutama pada pasien Prioritas 1 di RSUD Dr soetomo Surabaya . Kurangnya tingkat pengetahuan bidan tentang BLS merupakan salah satu faktor yang dapat memperlambat waktu tanggap bidan dalam menangani pasien Prioritas 1 sehingga resiko terjadinya kecacatan dan kematian akan semakin tinggi. Tujuan penelitian ini adalah mengetahui hubungan tingkat pengetahuan perawat tentang BLS dengan waktu tanggap pelayanan gawat darurat pada pasien Prioritas 1 di RSUD Dr soetomo Surabaya. Metodologi: Desain penelitian ini menggunakan metode analitik observasional dengan pendekatan Time Series. Populasi yang digunakan yaitu bidan Kamar Terima IGD OBGYN RSUD Dr soetomo Surabaya, pada bulan Mei 2017. Sampel diambil sebesar 21 responden dengan teknik Total Sampling. Pengambilan data dilakukan menggunakan kuesioner dan lembar observasi. Setelah data ditabulasi, kemudian dianalisis menggunakan uji statistik Spearman's Rho Correlation dengan $\rho \leq 0,05$. Hasil: Penelitian menunjukkan bahwa hampir sebagian (42,9\%) responden memiliki tingkat pengetahuan baik dan sebagian besar $(61,9 \%)$ responden memiliki waktu tanggap cepat. Berdasarkan hasil uji statistik diperoleh hasil ada hubungan tingkat pengetahuan bidan tentang BLS dengan waktu
\end{abstract}


tanggap pelayanan gawat darurat dengan $\rho=0,000$. Melihat hasil penelitian ini, dapat disimpulkan bahwa semakin baik tingkat pengetahuan bidan tentang BLS maka semakin cepat waktu tanggap pelayanan gawat daruratnya. Perlu adanya usaha peningkatan pengetahuan bidan tentang BLS melalui pelatihan dan workshop agar waktu tanggap Bidan semakin cepat.

Kata kunci: Pengetahuan, Basic Life Support, waktu tanggap, pelayanan gawat darurat, triase prioritas 1

BLS (Basic Life Support) adalah suatu pertolongan pertama yang harus segera dilakukan agar tidak terjadi kerusakan organ vital yang membuat pasien tidak tertolong. BLS dalam Unit Gawat Darurat diperlukan terutama untuk pasien yang termasuk dalam golongan Prioritas Satu (P1). Mengingat bahwa prinsip pelayanan gawat darurat adalah Time Saving is Life Saving, terutama pada pasien gawat darurat, tindakan yang cepat dan tepat perlu dilakukan oleh Bidan untuk menyelamatkan jiwa pasien. Menurut data yang ada di Kamar Terima Unit Gawat Darurat RS Dr Soetomo Surabaya tentang jumlah pasien Prioritas Satu (P1) selama bulan Oktober - Desember 2016, terdapat 297 pasien pada bulan Oktober 2016, 321 pasien pada bulan November 2016, dan 234 pasien pada bulan Desember 2016. Jumlah pasien Prioritas Satu (P1) selama bulan Oktober - Desember 2016 adalah 852 pasien dengan rata-rata 284 pasien tiap bulan (Nunuk. 2008)

Data lain menunjukkan bahwa pasien Prioritas Satu (P1) yang dilayani dengan waktu tanggap cepat atau tidak lebih dari 1 menit di Kamar Terima Unit Gawat Darurat RS dr Soetomo Surabaya sebanyak $75 \%$ atau 223 pasien dari 297 pasien pada bulan Oktober 2016, 82\% atau 263 pasien dari 321 pasien pada bulan November 2016, dan $78 \%$ atau 183 pasien dari 234 pasien pada bulan Desember 2016. Jumlah pasien Prioritas Satu (P1) selama bulan Oktober - Desember 2016 yang dilayani dengan waktu tanggap cepat atau tidak lebih dari 1 menit adalah 669 pasien dengan rata-rata 223 pasien tiap bulan.

Data di atas menunjukkan bahwa masih terdapat pelayanan gawat darurat pada pasien Prioritas Satu (P1) dengan waktu tanggap yang lambat atau lebih dari 1 menit. Adapun jumlah perawat di Kamar Terima Unit RS Dr. Soetomo Surabaya yang tercatat hingga bulan Desember 2016 sebanyak 22 orang. Jumlah yang mempunyai perbandingan yang sangat jauh dengan jumlah pasien Prioritas Satu (P1). Indikator keberhasilan tindakan medik dalam penanganan pasien Prioritas Satu (P1) yang dilakukan oleh bidan di Unit Gawat Darurat adalah waktu tanggap. Tujuan penelitian ini adalah menganalisis hubungan tingkat pengetahuan perawat tentang BLS dengan waktu tanggap pelayanan gawat darurat pasien Prioritas Satu (P1) di Kamar Terima Unit Gawat Darurat RS dr Soetomo Surabaya. Pengetahuan merupakan hasil dari tahu, dan ini terjadi setelah orang melakukan penginderaan terhadap suatu obyek tertentu. Tingkat Pengetahuan di dalam Domain Kognitif diantaranya: Tahu (Know), Memahami (Comprehension), Aplikasi (Application), Analisis (Analysis), Sintesis (Synthesis), Evaluasi (Evaluation). Gawat Darurat adalah waktu tanggap. Tujuan penelitian ini adalah menganalisis hubungan tingkat pengetahuan perawat tentang BLS dengan waktu tanggap pelayanan gawat darurat pasien Prioritas Satu (P1) di Kamar Terima Unit Gawat Darurat RS dr Soetomo Surabaya.

\section{BAHAN DAN METODE}

Desain penelitian yang digunakan analitik observasional dengan pendekatan Cross Sectional dimana dalam penelitian ini, Populasi dalam penelitian ini adalah semua bidan yang bertugas di Kamar Terima obgyn Unit Gawat Darurat RS Dr. Soetomo Surabaya sebesar 22 orang. Penelitian ini dilaksanakan pada tanggal 1-30 Mei 2017 di Kamar Terima Unit Gawat Darurat RS dr. Soetomo Surabaya. Sampel dalam penelitian ini adalah seluruh bidan yang bertugas di Kamar Terima Unit Gawat Darurat RS dr. Soetomo Surabaya yang memenuhi kriteria, Kriteria inklusi adalah bidan yang bertugas di Kamar Terima Obgyn Unit Gawat Darurat RS dr. Soetomo Surabaya yang bersedia menjadi responden. Kriteria eksklusi pada penelitian ini adalah bidan yang bertugas di Kamar Terima obgyn Unit Gawat Darurat RS dr Soetomo Surabaya namun saat ini sedang menjalankan tugas dinas ke luar atau sedang cuti. Besar sampel yang digunakan dalam penelitian ini adalah 21 orang, Kuesioner berisi 20 pertanyaan tentang BLS (Basic Life Support), terdiri dari 2 pertanyaan tentang pengertian BLS (Basic Life Support) pada pertanyaan nomor 1 dan 2, 5 per- 
tanyaan tentang prinsip dasar BLS (Basic Life Support) pada pertanyaan nomor 3 sampai 7, 14 pertanyaan tentang penatalaksanaan BLS (Basic Life Support) pada pertanyaan nomor 8 sampai 21 , dan 4 pertanyaan tentang waktu tanggap dalam BLS (Basic Life Support) pada pertanyaan nomor 22 sampai 25 , diperiksa, diolah dan di analisis secara statistik nonparametrik berdasarkan uji statistik Spearman's Rho Correlation menggunakan SPSS 16.0 for Windows dengan derajat kemaknaan $\rho<$ 0,05 . Artinya bila hasil uji statistik menunjukkan $\rho$ $<0,05$ maka $\mathrm{H}_{0}$ ditolak dan $\mathrm{H}_{1}$ diterima, artinya ada hubungan yang bermakna antara tingkat pengetahuan perawat tentang BLS (Basic Life Support) dengan waktu tanggap pelayanan gawat darurat pada pasien Prioritas Satu (P1) di Kamar Terima obgyn Unit Gawat Darurat RS Dr.Soetomo Surabaya.

Hasil uji statistik dengan menggunakan uji korelasi Spearman's Rho Correlation untuk mengetahui apakah ada hubungan diantara dua variabel yaitu tingkat pengetahuan perawat tentang BLS dengan waktu tanggap pelayanan gawat darurat pada pasien P1 didapatkan $\rho=0,000$. Hal ini menunjukkan bahwa $\rho \leq 0,05$ berarti $\mathrm{H}_{0}$ ditolak yang berarti terdapat hubungan antara tingkat pengetahuan perawat tentang BLS dengan waktu tanggap pelayanan gawat darurat pada pasien P1 di Kamar Terima obgyn Unit Gawat Darurat RS dr Soetomo Surabaya.

\section{HASIL PENELITIAN}

Tabel 1 Tabulasi Silang Pengetahuan Bidan tentang BLS

\begin{tabular}{llcc}
\hline No & Pengetahuan & f & \% \\
\hline 1 & Baik & 9 & 42,9 \\
2 & Cukup & 7 & 33 \\
3 & Kurang & 5 & 23,8 \\
\hline & Total & $\mathbf{2 1}$ & $\mathbf{1 0 0}$ \\
\hline
\end{tabular}

Tabel 2 Tabulasi Silang Waktu Tanggap Pelayanan Gawat Darurat

\begin{tabular}{llcc}
\hline No & Waktu Tanggap & f & \% \\
\hline 1 & Cepat & 12 & 57,1 \\
2 & Lambat & 9 & 42,9 \\
\hline & Total & $\mathbf{2 1}$ & $\mathbf{1 0 0}$ \\
\hline
\end{tabular}

Berdasarkan data hasil penelitian, dari 21 responden yang ada didapatkan hampir sebagian
$(42,9 \%)$ responden memiliki tingkat pengetahuan baik dan seluruhnya mempunyai waktu tanggap cepat. Sebagian kecil $(33,3 \%)$ responden memiliki tingkat pengetahuan cukup, sebagian besar diantaranya $(57,1 \%)$ mempunyai waktu tanggap dan sisanya $(42,9 \%)$ mempunyai waktu tanggap lambat. Sisa responden $(23,8 \%)$ lainnya memiliki tingkat pengetahuan kurang dan seluruhnya (100\%) mempunyai waktu tanggap lambat.

\section{PEMBAHASAN}

Hasil analisa data dengan uji statistik Spearman's Rho Correlation diperoleh hasil $\rho=$ 0,000 . Dimana $\rho \leq 0,05$ maka $\mathrm{H}_{0}$ ditolak. Artinya ada hubungan antara tingkat pengetahuan perawat tentang BLS dengan waktu tanggap pelayanan gawat darurat pada pasien (P1). Hal ini membuktikan bahwa semakin baik tingkat pengetahuan perawat tentang BLS maka semakin cepat waktu tanggap pelayanan gawat darurat yang diperlukan untuk menangani pasien (P1).

Berdasarkan data hasil penelitian, dari 21 responden yang ada didapatkan hampir sebagian $(42,9$ $\%$ ) responden memiliki tingkat pengetahuan baik dan seluruhnya mempunyai waktu tanggap cepat. Sebagian kecil $(33,3 \%)$ responden memiliki tingkat pengetahuan cukup, sebagian besar diantaranya $(57,1 \%)$ mempunyai waktu tanggap dan sisanya $(42,9 \%)$ mempunyai waktu tanggap lambat. Sisa responden $(23,8 \%)$ lainnya memiliki tingkat pengetahuan kurang dan seluruhnya (100\%) mempunyai waktu tanggap lambat.

Menurut Moewardi (2003) dapat dipahami bahwa salah satu faktor yang mempengaruhi keberhasilan waktu tanggap sangat tergantung kepada kualitas tim medis dan tim perawat untuk menyelamatkan nyawa atau mencegah kecacatan. Oleh karena itu kualitas tim perawat dalam memberikan pelayanan gawat darurat pada pasien P1 di Kamar Terima Unit Gawat Darurat dipengaruhi oleh tingkat pengetahuan perawat tentang BLS.

Artinya semakin baik tingkat pengetahuan perawat tentang BLS maka akan semakin cepat pula waktu tanggap pelayanan gawat darurat pada pasien (P1). Sehingga kemungkinan terjadi kecacatan (morbidity) atau bahkan kematian (mortality) pada pasien akan semakin kecil. Dari pengalaman dan penelitian terbukti bahwa perilaku yang didasari oleh pengetahuan akan lebih langgeng daripada perilaku yang tidak didasari oleh pengetahuan (Notoadmodjo, 2003) dan yang dimaksud perilaku disini adalah 
waktu tanggap pelayanan gawat darurat pada pasien P1 yang dilakukan oleh perawat.

Banyak cara yang dapat dilakukan untuk meningkatkan pengetahuan perawat tentang BLS dan waktu tanggap pelayanan gawat darurat oleh perawat. Antara lain, mengikuti pelatihan dan workshop keperawatan dengan tema BLS yang diadakan oleh pihak rumah sakit tempat perawat bekerja maupun pihak lain.

\section{SIMPULAN DAN SARAN}

\section{Simpulan}

Terdapat hubungan tingkat pengetahuan bidan tentang BLS (basic life support) dengan waktu tanggap pelayanan gawat darurat pada pasien di IRD Obgyn RSUD dr Soetomo Surabaya.

\section{Saran}

Bagi tenaga kesehatan khususnya Bidan agar lebih mengoptimalisasikan pengetahuan dan keterampilan tentang Basic Life Support (BLS) sehingga waktu tanggap pelayanan gawat darurat semakin cepat dan pelayanan semakin efektif.

\section{DAFTAR RUJUKAN}

Moewardi. 2003. Materi Pelatihan PPGD. Surakarta. Notoatmodjo, Soekidjo. 2003. Pendidikan dan Perilaku Kesehatan. Jakarta : Rineka Cipta. Hal: 114, 120 , 121, 122, 124, 125, 126, 127.

Notoatmodjo, Soekidjo. 2002. Metodologi Penelitian Kesehatan. Jakarta : Rineka Cipta. Hal: 10.

Nunuk dan Agus. 2008. Perbedaan Waktu Tanggap Tindakan Keperawatan Pasien Cedera Kepala Kategori I - V di Instalasi Gawat Darurat RSUD Dr. Moewardi Berita Ilmu Keperawatan. Vol 1. No. 2. Juni 2008. Hal. 69-74. 